\title{
The effectiveness of attention improving multimedia package on selective attention of children with ADHD
}

\author{
Baburaj PT ${ }^{1}$, Princy George ${ }^{2}$, Anjaly $\mathrm{KS}^{3 *}$
}

\section{*Corresponding author:}

${ }^{3}$ Anjaly KS. Research scholar, School of Behavioural sciences, MG university, Kottayam., MPhil Scholar 2, IUCDS, MG University.

Email: anjalyks29486@gmail.com ORCID

\author{
${ }^{1}$ Associate Professor, School of Behavioural sciences, MG \\ university, Kottayam. \\ ${ }^{2}$ Research scholar, School of Behavioural sciences, MG \\ university, Kottayam.
}

\section{Information about the article:}

Received: Jan. 17, 2019

Accepted: Feb. 20, 2019

Published online: Dec. 27, 2019

\section{Publisher}

Nepal Health Research Society, Bahundhara -6,
Gokarnesowor Municipality, Kathmandu, Nepal eISSN 2382-5545, ISSN 2676-1343 (Print)

(C) The Author(s). 2019

Content licensing: CC BY 4.0

\section{ABSTRACT \\ Background \\ The aim of present study is to improve the selective attention of children with attention deficit hyperactivity disorder (ADHD), using a computer application.}

\section{Materials and methods}

The investigator developed a computer assisted program (Attention Improving Multimedia Package) to improve the selective attention of children with ADHD. The training package consists of performance based and timed activities aimed to improve the accuracy, concentration and speed of work of children with ADHD. After developing the tool, the investigator approached the school authorities. The purpose and need of the study were explained to the Principals and teachers. The samples were selected by assessing the students using ADHDSRS. The school rater option was used. The investigator selected 20 students who had been screened as "at risk" and "high risk" of ADHD in school rater option as explained in the ADHD- SRS manual. The investigator selected 20 students who are "at risk" and "high risk” of ADHD from both sexes. The subjects were the 5th, 6th and 7th grade students aged 10, 11 and 12 selected from Govt. H S S, Puthoor. Then the samples were randomly assigned to experimental and control group. Each group consisted of 10 subjects. Both the experimental and control group were assessed to understand their baseline performance. The d2 test of attention was administered to both groups. Before administering the test, the procedure and purpose were explained. Socio- demographic details were noted in the space given. After completing the $\mathrm{d} 2$ test of attention, filled recording blanks were collected and checked whether it is completed or not. Then the AIMP were given to the experimental group in a separate classroom individually. Before administering the AIMP, a rapport was created with subject. The procedures and importance of AIMP was explained to the subjects. The subjects were allowed to sit comfortably in front of the computer and the room was free from any disturbances.

After the successful completion of the intervention, a posttest was conducted for both experimental and control group. To find out the sustainability of attention after the intervention, the investigator conducted a delayed post-test after one week of post-test. There were 5 sessions. In the first session the subjects were asked to complete LEVEL 1 activity. In the second session, the subject was informed to complete the LEVEL 1 at first and then the LEVEL 2 activities. The third, fourth and fifth sessions were administered by starting from the LEVEL 1 . By repeating the activities, the subject could easily complete the previous level of activities faster than earlier. The time taken to complete was recorded on each session, so the administer can observe the improvement of subject.

\section{Results}

The mean rank and Wilcoxon $\mathrm{Z}$ value of pre-test and posttest scores on accuracy of performance of experimental group are 3.00 and 2.121 respectively. The $\mathrm{Z}$ value of experimental group is significant at 0.05 level.

\section{Conclusion}

Hence, the null hypothesis, "there is no significant difference in the accuracy of performance of experimental group before and after intervention" is rejected and is concluded that there is a significant improvement in accuracy after intervention.

\section{Keywords}

Attention improving multimedia package, attention deficit hyperactivity disorder, school student 